Article

\title{
Osmolality of Components and Their Application in the Design of Functional Recovery Drinks
}

\author{
Anna Sadowska ${ }^{1, * \mathbb{D}}$, Franciszek Świderski ${ }^{1}$ and Wacław Laskowski ${ }^{2}$ \\ 1 Department of Functional and Organic Food, Institute of Human Nutrition Sciences, \\ Warsaw University of Life Sciences, Nowoursynowska Str. 159c, 02-776 Warsaw, Poland; \\ franciszek_swiderski@sggw.edu.pl \\ 2 Department of Food Market and Consumer Research, Institute of Human Nutrition Sciences, \\ Warsaw University of Life Sciences, Nowoursynowska Str. 159c, 02-776 Warsaw, Poland; \\ waclaw_laskowski@sggw.edu \\ * Correspondance: anna_sadowska@sggw.edu.pl; Tel.: +48-22-59-37-040
}

Received: 30 September 2020; Accepted: 27 October 2020; Published: 29 October 2020

check for updates

\begin{abstract}
Measuring the osmolality of electrolytes, carbohydrates, and other components that contain them, can be very helpful in the design of functional recovery drinks. This study aimed to develop functional recovery drinks based on natural fruit components with the addition of electrolytes and carbohydrates to improve water and electrolyte balance and provide energy after intense physical exertion, as well as ensuring a high content of bioactive ingredients and being of a good sensory quality. The study material consisted of blackcurrant fruit powders obtained by freeze-drying and spray-drying, along with other components such as electrolytes and carbohydrates. The osmolality of the fruit components was measured in aqueous solutions with concentrations from 2.5 to $10 \%$, as well as electrolytes at 0.1 to $4.0 \%$ and carbohydrates from 1 to $30 \%$. The sensory quality of drinks was assessed using a scaling method. The content of polyphenols and antioxidant properties were measured spectrophotometrically and the vitamin $C$ content by high-pressure liquid chromatography. Based on the obtained results, five versions of recovery drinks were prepared of defined compositions. These drinks contained fruit powders ranging from 3 to $7 \%$, glucose at 1 to $5 \%$, sucrose $5 \%$, and added electrolytes ranged 0.1 to $0.2 \%$ for $\mathrm{NaCl}$ and $\mathrm{KCl}$ at $0.025 \%$. Their osmolalities ranged from 401 to $564 \mathrm{mOsm} / \mathrm{kg} \mathrm{H}_{2} \mathrm{O}$, the total polyphenol content was 43 to $62 \mathrm{mg} \mathrm{GAE} / 100 \mathrm{~mL}$, and vitamin $\mathrm{C}$ 26 to $35 \mathrm{mg} / 100 \mathrm{~mL}$. All drinks possessed satisfactory sensory quality. It was established that it is possible to obtain fruit recovery drinks containing defined amounts of electrolytes, carbohydrates, and osmolality values recommended for this type of drink.
\end{abstract}

Keywords: osmolality; fruit powders; recovery drinks

\section{Introduction}

Osmolality can be an important indicator for determining how useful beverages are for hydrating the body [1]. Its measurement is particularly appropriate for cases of dehydration, sodium/potassium disorders, glucose fluctuations, exogenous poisoning, adrenal insufficiency, and neurological injury, as well as in physical exercise and other challenging circumstances [2]. Sports drinks are an important part of the functional beverages available on the market which are retailed as drinks that replenish electrolytes lost during exercise, supply carbohydrates, prevent dehydration, and sustain endurance capacity [3-6]. Intensive exercise may lead to sweat rates of $1 \mathrm{~L} / \mathrm{h}$, whilst exercising at high temperatures may increase sweat loss of $>2 \mathrm{~L} / \mathrm{h}$. Progressive dehydration is likely in those sweating over long time periods that can produce metabolic or physiological effects such as reduced blood flow, impaired heat exchange, reduced oxygen supply to muscle cells, increased stress hormone levels, and enhanced 
glycogen breakdown rates in the liver and muscle [7-10]. When there is an insufficient fluid intake, sweating becomes also limited which at high ambient temperatures may cause the body to overheat. Any ongoing dehydration generally may constitute a threat to health and performance capacity will become reduced. Controlling the body's hydration status is thus very important. The two predominant factors that lead to premature fatigue are depletion of the body's carbohydrate reserves and losses of water and electrolytes via sweating. Being appropriately hydrated is, therefore, necessary to ensure that the body functions efficiently when engaged in sporting activities through consuming beverages of suitable osmolalities intended for sportspersons; the main purpose being to replenish any electrolytes lost during exercise, supplying carbohydrates, preventing dehydration, and sustaining endurance capacity [3-6,11]. Isotonic drinks have osmolalities ranging from 275 to $295 \mathrm{mOsm} / \mathrm{kg}$ water and are of similar osmotic pressure to body fluids. There are also various other "light" sugar-free drinks/mineral waters with osmolalities lower than $275 \mathrm{mOsm} / \mathrm{kg}$ water which are termed "hypotonic". Unlike isotonic beverages, these are however unable to quickly improve water-electrolytes because of their lower electrolyte concentrations. Hypotonic drinks are in fact recommended for people performing moderate work or those engaging in not too intensive physical exercise nor of long duration without any excessive sweating. Current oral rehydration therapy guidelines suggest that hypotonic carbohydrate $(\mathrm{CHO})$-electrolyte solutions should be drunk whenever there is a need for rapidly replacing fluid [12-14]. If, however, the aim is to maintain fluids balance over prolonged periods, then drinking such hypotonic $\mathrm{CHO}-$ electrolyte solutions may be inappropriate because of differences in urine volume excreted. Electrolytes, especially sodium, play a major role in fluid homeostasis where the amounts of sodium and chloride lost through excretion are relatively large compared to losses in magnesium, calcium, and potassium. Rehydration with large amounts of plain water may cause hyponatremia (i.e., low blood sodium) [7,15-17], but not hypokalemia (i.e., low blood potassium) nor hypomagnesemia (i.e., low blood mag-magnesium). Gisolfi et al. 1992 [18] compared water absorption rates in a segment of the small intestine after perfusion with solutions of either isotonic sodium chloride or isotonic $\mathrm{CHO}$-electrolyte (i.e., $8 \%$ sucrose and $16 \mathrm{mmol} / \mathrm{L} \mathrm{Na}$ ) and found that sodium chloride alone only marginally affected such rates, whereas $\mathrm{CHO}$ with sodium chloride increased the rates by around five-fold. Apart from sodium chloride, (and only in the presence of $\mathrm{CHO}$ ), no other electrolytes affect water absorption [19]. Recent studies have shown that the $\mathrm{CHO}$ content is the most important factor affecting the rate of gastric emptying of rehydration drinks. $\mathrm{CHO}$ solutions at concentrations of $>8$ to $10 \%(\mathrm{w} / \mathrm{v})$ significantly inhibit gastric emptying, thereby reducing fluid available for absorption, and should therefore not be used whenever there are sweat losses and the body's resulting fluid requirements are high. Regular soft drinks and fruit juices containing large amounts of $\mathrm{CHO}$ therefore cannot be used as functional rehydration drinks; for example, most fruit juices and soft drinks contain $>100 \mathrm{~g} \mathrm{CHO} / \mathrm{I}$. This is also the case for designer energy drinks where osmolalities range from 500 to $800 \mathrm{mOsm} / \mathrm{kg} \mathrm{H}_{2} \mathrm{O}$, which reduces rapid fluid uptake by the body. Studies [7,19-21] on performance and fatigue recommend carbohydrate concentrations ranging from 60 to $80 \mathrm{~g} / \mathrm{L}$ in rehydration drinks as providing optimal support for performance. Whenever fluid losses are relatively small, it is possible to increase a drink's $\mathrm{CHO}$ content to a maximum of $150 \mathrm{~g} / \mathrm{L}$ if an optimal CHO supply of 30 to $60 \mathrm{~g} / \mathrm{h}$ for performance support is the desired prime criterion. To this amount of $\mathrm{CHO}$, sportspersons should then add appropriate amounts of water tailored to their individual needs and preferences. To keep the osmolality as low as possible, long-chain glucose polymers and/or maltodextrins are preferred because strongly hypertonic drinks will greatly increase secretion of fluid from the blood into the gut, thereby increasing the risk of gastrointestinal discomfort and diarrhea [7]. Sports drinks having a $>8 \% \mathrm{CHO}$ content may slow down gastric emptying and intestinal absorption during exercise compared to those with lower $\mathrm{CHO}$ concentrations. There appears to be no difference in rates of gastric emptying or fluid absorption between water and sports drinks when carbohydrate concentrations are between $4 \%$ and $8 \%$ [3]. Studies of $\mathrm{CHO}$ on sports performance and fatigue indicate that the minimum supply of $\mathrm{CHO}$ should be $>20 \mathrm{~g} / \mathrm{h}$ [7]. A study by Evans et al. (2009) [12] demonstrated that a hypertonic 10\% glucose-electrolyte solution of about $667 \mathrm{mOsm} / \mathrm{kg}$ was more effective in maintaining a state of euhydration after exercise-induced dehydration of about $1.9 \%$ 
body mass than a $2 \%$ glucose solution with an osmolality of about $193 \mathrm{mOsm} / \mathrm{kg}$ and a $0 \%$ glucose solution with an osmolality of about $79 \mathrm{mOsm} / \mathrm{kg}$. The literature reflects the possible risks of compounds, including sugars, caffeine, glycerol, and vitamin B2 found in sports drinks and energy drinks ingested by athletes and synergistic or antagonistic interactions of components of sports drinks [22]. Regarding dental health and sport dietary drinks, this study related the dental decay to the consumption of sports drinks with low $\mathrm{pH}$ [11]. Some of these beverages have cariogenic properties due to their sugar content. Furthermore, long-term exposure of the body to an excess of simple sugars is associated with the development of obesity, insulin resistance, and diabetes. In the case of caffeine, the literature underlines some adverse effects including nervousness, irritability, anxiety, and others. Concerning vitamin B2, one case report indicated suspected anaphylaxis after the intake of this ingredient as part of an energy drink. Several components of the drinks used by athletes (sports drinks, energy drinks, juices, and milk) can interact among themselves after the intake of different drinks causes negative effects such as side effects or decreases in activity. For example, drinks containing Ca such as milk significantly decrease $\mathrm{Fe}$ absorption, but positive interactions are also possible; for example, orange juice significantly increases Fe absorption. The most active ingredient present in energy drinks is caffeine, which is able to produce synergistic and reinforced stimulant effects in combination with guarana, ginseng, and taurine. Mixtures of different monosaccharides and disaccharides (glucose, fructose, and sucrose) interact, increasing carbohydrate absorption and oxidation during exercise more than themselves alone [11,22].

There is little literature data on the design of the recovery drinks composition and data regarding the dependence of regressive osmolality of electrolytes, CHOs, or fruit-based components on their concentrations in solution. Existing data are mainly concerned with measuring $\mathrm{CHO}$ osmolalities in physiological studies on body/animal hydration or those found in various beverages [2,3,22]. The literature indicates that a novel assortment of recovery drinks can be designed based on fruit powders with electrolyte additives for ensuring optimal rates of rehydration and delivering calories after exercising. It is thus assumed that investigating the relationships between regressive osmolalities with the concentrations of beverage components (such as electrolytes, $\mathrm{CHOs}$, and fruit powders) would greatly aid in designing appropriate compositions of recovery drinks.

\section{Materials and Methods}

\subsection{Materials}

The test materials were the components of recovery drinks consisting of $\mathrm{CHOs}$ such as glucose, sucrose, and maltodextrin as well as sodium chloride, potassium chloride, citric acid, and blackcurrant powders obtained by freeze-drying and spray-powdering methods. Blackcurrant used for drying methods were of the same origin.

The recipe composition of beverages was developed by the method of successive approximations by making a series of tests based on the base composition containing water, glucose in the amount of 1 to $5 \%, \mathrm{NaCl} 0.1 \%$, and $\mathrm{KCl} 0.025 \%$, which are the reference amounts given in the literature [7]. The powders were added in an amount ranging from $3 \%$ to $7 \%$ by making osmolality measurements. Based on the obtained osmolality results, the maximum levels of the addition of powders were established to obtain an osmolality of beverages not higher than $600 \mathrm{mOsm} / \mathrm{kgH}_{2} \mathrm{O}$ (Table 1).

Table 1. Recipe compositions of designed drinks.

\begin{tabular}{|c|c|c|c|c|c|}
\hline Ingredient $(\mathrm{g} / 100 \mathrm{~mL})$ & Version 1 & Version 2a & Version $2 b$ & Version 3 & Version 4 \\
\hline Lyophilized powder of blackcurrant & 3 & 4 & 4 & - & - \\
\hline Spray-dried powder of blackcurrant & - & - & - & 7 & 6 \\
\hline Glucose & 5 & 5 & - & 1 & 3 \\
\hline Sucrose & - & - & 5 & - & - \\
\hline $\mathrm{NaCl}$ & 0.2 & 0.1 & 0.1 & 0.1 & 0.1 \\
\hline $\mathrm{KCl}$ & 0.025 & 0.025 & 0.025 & 0.025 & 0.025 \\
\hline Water & 91.775 & 90.875 & 90.875 & 91.875 & 90.875 \\
\hline
\end{tabular}




\subsection{Methods}

The following measurements were then performed on each designed drink: osmolality, total extract content, $\mathrm{pH}$, acidity, polyphenols and vitamin $\mathrm{C}$ content, antioxidant activity, and sensory quality.

\subsubsection{Powder Preparation}

The freeze-dried powders were obtained using Alpha Model 1-4 LSC liofilizator (Martin Christ $\mathrm{GmbH}$, Osterode am Harz, Germany) (initially frozen at $-30^{\circ} \mathrm{C}$ and time $48 \mathrm{~h}$, process pressure $10 \mathrm{~Pa}$, temperature in the drying chamber $-50{ }^{\circ} \mathrm{C}$ and shelf temperature $21^{\circ} \mathrm{C}$, and time $48 \mathrm{~h}$ ).

After the convective or freeze-drying processes, the dried material was ground to a powder using a grinder with grinding knives (MKM 6003, Bosch, Stuttgart, Germany).

The spray-dried powders were obtained from blackcurrant juice with the addition of $60 \%$ maltodextrin carrier (dextrose equivalent of DE 12) at air temperatures of $160{ }^{\circ} \mathrm{C}$ for inlets and $90{ }^{\circ} \mathrm{C}$ for outlets, the $0.7 \mathrm{~mm}$ diameter dispersing nozzle was used (Buchi Mini Spray Dryer B-290, Flawil, Switzerland).

\subsubsection{Osmolality}

Osmolalities were determined by freezing point depression using an OS-3000 Osmometer (Trident med, Warsaw, Poland). The readings were expressed as $\mathrm{mOsm} / \mathrm{kg}$ water. The osmolality was measured for the following solutions: 0.1 to $2.0 \%$ sodium chloride, 0.1 to $4.0 \%$ potassium chloride, 1 to $10 \%$ glucose, 1 to $15 \%$ sucrose, 1 to $30 \%$ high-sugar maltodextrin, 0.1 to $9 \%$ citric acid, 2.5 to $10 \%$ blackcurrant powders, and designed recovery drinks.

\subsubsection{The Soluble Solids Content}

The soluble solids content at Brix was measured with a telescope refractometer (EclipseProfessional, Bellingham + Stanley Ltd., Saitama, Kent, Great Britain).

\subsubsection{The $\mathrm{pH}$}

The $\mathrm{pH}$ was measured using a Laboratory $\mathrm{pH}$-meter (Elmetron CP-511, Elmetron, Zabrze, Polska).

The acidity of the designed recovery drinks was determined with the potentiometric method in accordance with PN-EN 12147:2000 [23]. The total acidity of the drinks was converted to citric acid.

\subsubsection{The Antioxidant Activity}

The antioxidant activity of the designed recovery drinks was determined by using the ABTS $+\bullet\left(2,2^{\prime}-\right.$ azino-bis-3-ethylben-zothiazoline-6-sulphonic acid) radical cation assay according to the modified method of Re et al. (1999) [24]. A certain quantity of the tested solutions, which was determined earlier by a designated dilution scheme, was drawn into a $10 \mathrm{~mL}$ glass test tube and $3.0 \mathrm{~mL}$ of radical cations ABTS $+\bullet$ in PBS solution was added. The absorbance was measured after exactly 6 min of incubation at room temperature at $734 \mathrm{~nm}$ with the use of a spectrophotometer (UV/Vis UV-6100A, Metash Instruments Co., Ltd., Shanghai, China). The results were represented as TEAC (Trolox Equivalent Antioxidant Capacity) mmol Trolox in $100 \mathrm{~g}$ of each drink.

\subsubsection{The Total Content of Polyphenols}

The total content of polyphenols in the designed recovery drinks was determined by using the Folin-Ciocalteu (F-C) reagent, according to the modified Singleton and Rossi (1965) method [25]. A certain quantity of the tested extract solution, which was determined earlier by a designated dilution scheme, was drawn into a $50 \mathrm{~mL}$ flask, then $2.5 \mathrm{~mL}$ of the F-C reagent and $5.0 \mathrm{~mL}$ of $20 \%$ sodium carbonate were added and finally made up to volume with distilled water. The samples were incubated for $30 \mathrm{~min}$ at room temperature with no light access. The absorbance was measured at $720 \mathrm{~nm}$ with the use of a spectrophotometer (UV/Vis UV-6100A, Metash Instruments Co., Ltd., Shanghai, China). The results were represented as mg GAE (Gallic Acid Equivalent) in $100 \mathrm{~g}$ of each drink. 


\subsubsection{Vitamin C}

Vitamin C was measured as the sum of ascorbic acid and dehydroascorbic acid by HPLC with UV detection at a wavelength of $245 \mathrm{~nm}$ and a mobile phase flow rate of $0.8 \mathrm{~mL} / \mathrm{min}$. Total vitamin C content was determined following extraction for ascorbic acid and dehydroascorbic acid and then reduction using the dithiothreitol reagent. HPLC was performed with a UV2487 detector and separation by an RP Symmetry C18.5 $\mu \mathrm{m}$. A $4.6 \times 150 \mathrm{~mm}$ column at a temperature of $25^{\circ} \mathrm{C}$ was carried out, where the injection volume varied between 10 and $30 \mu \mathrm{L}$. The results are expressed in $\mathrm{mg}$ of vitamin $\mathrm{C} / 100 \mathrm{~g}$ of each drink.

All physicochemical determinations were performed in triplicate.

\subsubsection{The Sensory Analysis}

The sensory characteristic of the designed recovery drinks was determined using a scaling method in accordance with ISO PN-EN ISO 13299:2016-05 (2016) [26] by an eight-person sensory panel of qualified assessors who were experts according to PN-EN ISO 8586:2014-03 [27]. Members of the panel had good knowledge of all of the sensory methods (theoretical and practical). The evaluations were carried out in two sessions. Six quality parameters were selected to evaluate the drinks: blackcurrant flavor, sour taste, sweet taste, salty taste, particle palpability, and overall quality. The intensity of the above-mentioned parameters was assessed on an unstructured 10-point scale in contractual units (cu.). Ratings were performed at the Laboratory of Sensory Analysis which meets all the criteria specified in the PN-EN ISO 8589:2010/A1:2014-07 [28] standard.

\subsubsection{The Statistical Analysis of the Data Obtained}

Statistica 13.0 (Tibco Software Inc., Palo Alto, CA, USA) software was used for all statistical processing. A one-way analysis of variance (ANOVA) with the post hoc analysis of the Duncan test at the significance level $p<0.05$ was used.

\section{Results and Discussion}

\subsection{Osmolality of Recovery Drinks' Components}

The osmolalities of sodium chloride and potassium chloride solutions were measured at respective concentration ranges of 0.1 to $2.0 \%$ and 0.1 to $4.0 \%$. Figure $1 \mathrm{a}$, b show the effect of increasing concentration on the osmolalities of these salts, where linear increases in osmolalities were observed with the potassium chloride showing an insignificantly lower rate; the coefficients of variation $\left(\mathrm{r}^{2}\right)$ were closely similar at respectively, 0.998 and 0.997 , for $\mathrm{NaCl}$ and $\mathrm{KCl}$. A similar linear relationship was obtained in the previous studies on the influence of the concentration of minerals in beverages on their osmolality [1]. The data presented in Figure 1 show that the tested salts are characterized by high osmolality. To obtain the osmolality of an aqueous solution corresponding to isotonic drinks, the concentration of $\mathrm{NaCl}$ should be about $0.8 \%$ and $\mathrm{KCl} 1.2 \%$. The recommended maximum content in sports drinks of these electrolytes is much lower, amounting to sodium $1100 \mathrm{mg} / \mathrm{L}$ and potassium $225 \mathrm{mg} / \mathrm{L}$. (Brouns). These values increase the osmolality of water drinks by approximately $60 \mathrm{mOsm} / \mathrm{kg} \mathrm{H}{ }_{2} \mathrm{O}$. These fairly low salt additions in beverages compared to the so-called salty foods, where the $\mathrm{NaCl}$ content is usually above $1 \%$ (e.g., broths and soups), make both the taste and ensuring proper hydration of the body of a physically active person [7]. 


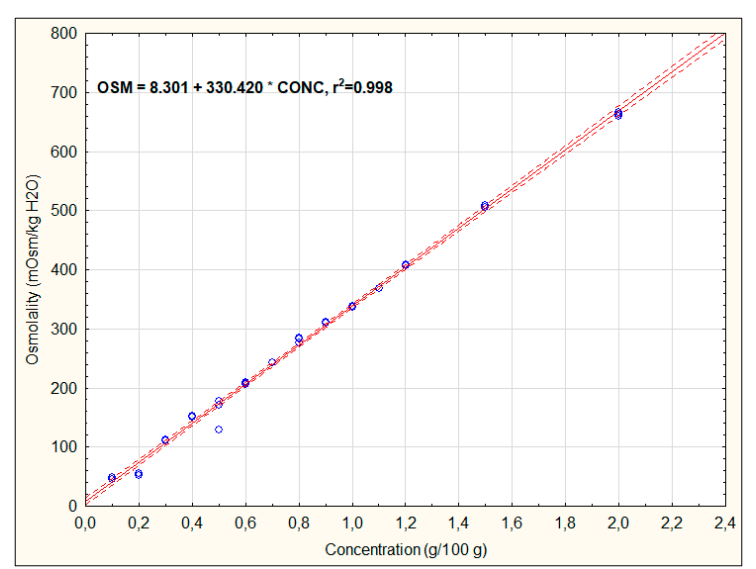

(a)

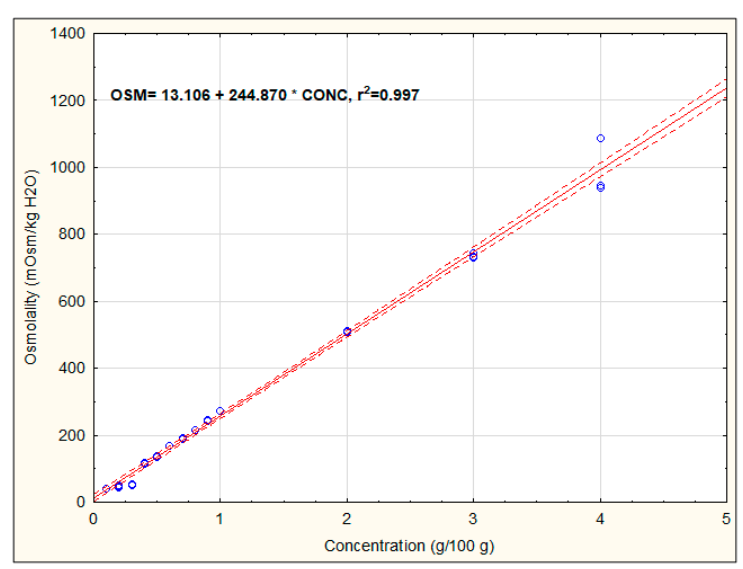

(b)

Figure 1. Sodium chloride (a) and potassium chloride (b) osmolalities in aqueous solution.

Osmolalities of citric acid solutions were measured at 0.1 to $9 \%$ concentrations shown in Figure 2, which increased in a linear fashion similar to the previous analytes. The amounts of citric acid used in sport drinks as an acidity regulator are usually in the range of 0.2 to $0.6 \%$ which has some slight effect on their osmolality.

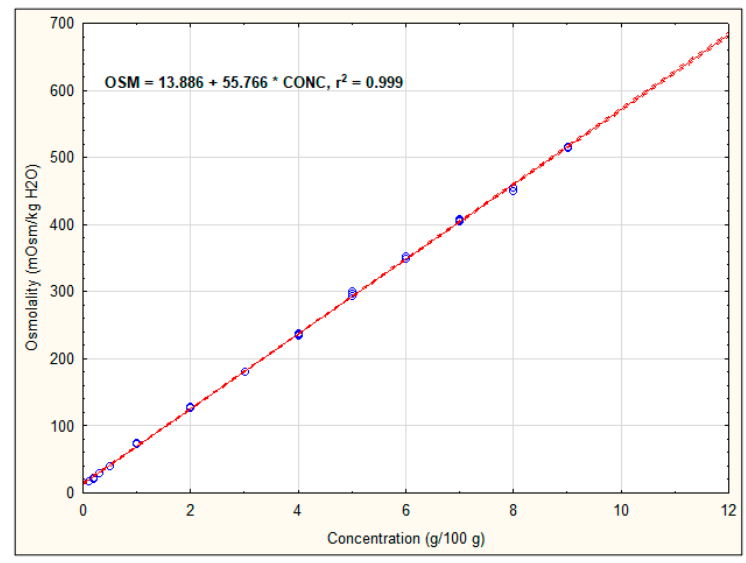

Figure 2. Citric acid osmolalities in aqueous solution.

In the group of sugars, the osmolality was determined for glucose, sucrose, and high-sugar maltodextrin in water solutions (Figure $3 \mathrm{a}-\mathrm{c}$ ). As in the case of electrolytes, a linear relationship was obtained between osmolality and $\mathrm{CHO}$ concentration in the tested range, from 1 to $10 \%$ for glucose, 1 to $15 \%$ for sucrose and 1 to $30 \%$ for maltodextrin. A similar linear relationship between the osmolality and the extract of the tested market beverages was obtained in Sadowska et al. (2017) [1] study. The tested $\mathrm{CHOs}$ were characterized by a high differentiated osmolality. The highest values of osmolality for the same concentrations were observed for glucose, followed by sucrose to the lowest for maltodextrin. The present study is consistent with the study of Santos et al. (2010) [29] which showed the highest osmolalities for glucose and sucrose compared with fructose in coconut water. $\mathrm{CHO}$, thanks to a relatively low osmolality (as compared to electrolytes), can be used in large amounts, enabling the achievement of satisfactory sensory quality in beverages with an addition of electrolytes with a salty-bitter taste. To achieve osmolality of an isotonic drink, $5 \%$ glucose, $8.5 \%$ sucrose, and as much as $18 \%$ maltodextrin are needed. Brouns and Kovacs (1997) [7] states that the optimal CHO concentration to allow for both rapid fluid uptake and appropriate energy delivery is supposed to be in the range of 60 to $80 \mathrm{~g} / \mathrm{L}$ ( 5 to $8 \%$ ). 


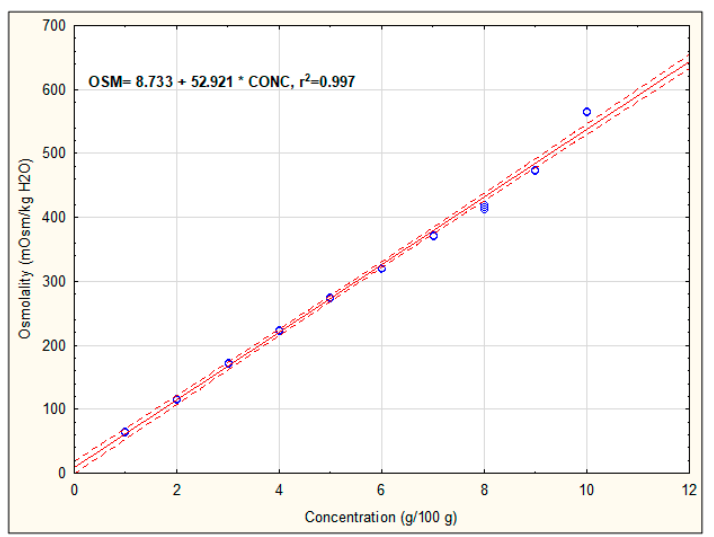

(a)

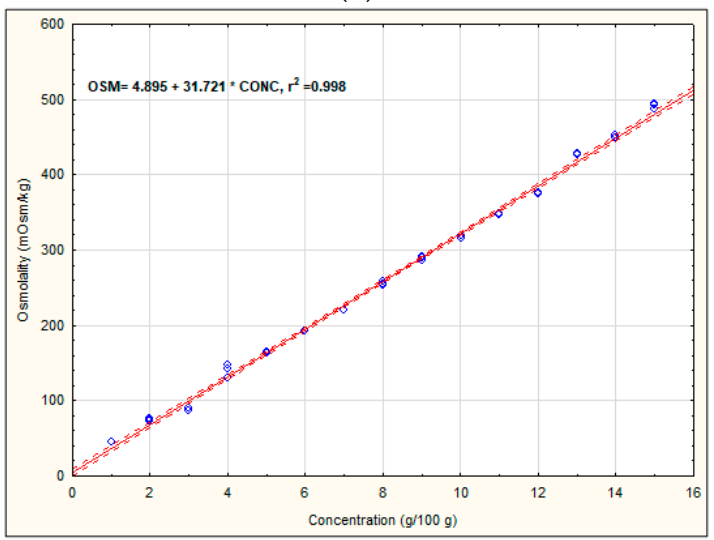

(b)

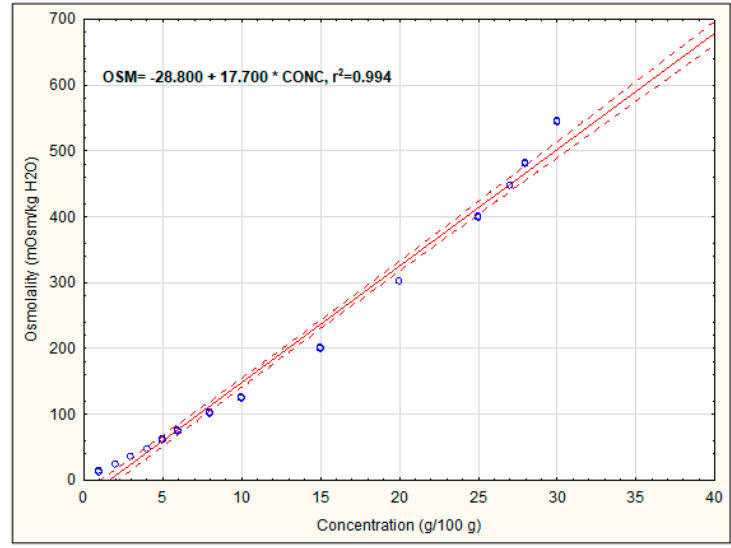

(c)

Figure 3. Glucose (a), sucrose (b), and high-sugar maltodextrin (DE 23-32) (c) osmolalities in aqueous solution.

Figure $4 \mathrm{a}, \mathrm{b}$ shows the osmolality for blackcurrant powders. Osmolalities were tested for blackcurrant powders obtained by using two drying methods at concentrations from 2.5 to $10 \%$. The freeze-dried powders had greater osmolality than those obtained through the spray-drying method, which arose due to the presence of the maltodextrin carrier in the latter (60\%) resulting in the decreased osmolalities. The tested powders are characterized by a much lower osmolality compared to $\mathrm{CHO}$ (Figure 2). Their osmolality is determined by the content of soluble solids, especially glucose and sucrose. To obtain the osmolality characteristic of an isotonic drink, it is necessary to add a freeze-dried powder in an amount of about $9 \%$ and a powder obtained by spray-drying approximately $11 \%$. Such a high level of addition of powders with high acidity was not appropriate for sensory reasons [30]. 


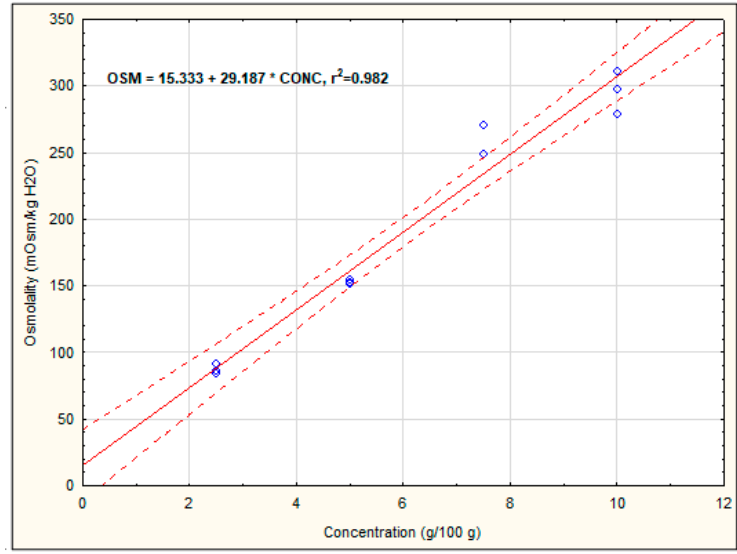

(a)

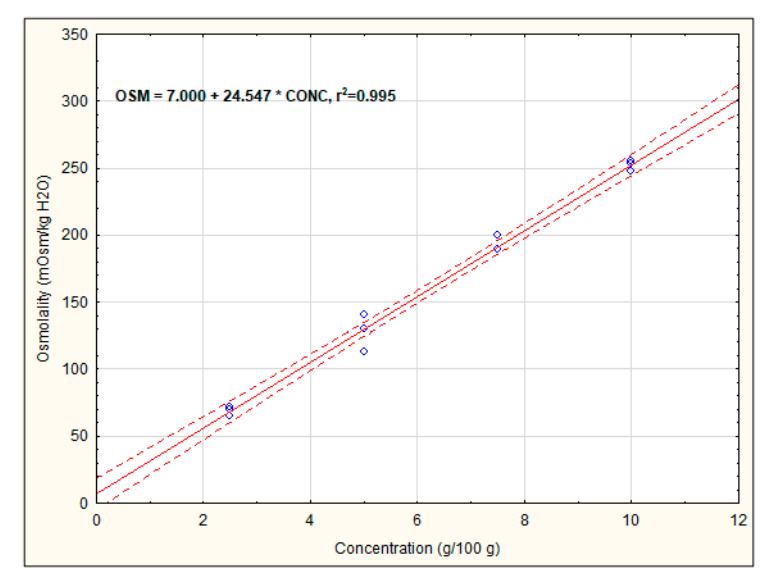

(b)

Figure 4. Blackcurrant freeze-dried (a) and spray-dried (b) powder osmolalities in aqueous solution.

\subsection{Determining the Composition and Physico-Chemical Properties of Recovery Drinks}

The composition of five fruit juice drinks intended for body regeneration after intensive physical exercise was established, based on the recognized relationships between osmolality and concentrations of electrolytes $\left(\mathrm{Na}^{+}\right.$and $\left.\mathrm{K}^{+}\right)$, citric acid, and blackcurrant powders obtained by the two methods (i.e., freeze-drying and spray-drying), as well as accounting for the literature data (Table 1). It was assumed that $\mathrm{CHO}$-electrolytes designed compositions should ensure the body's adequate hydration after intensive physical exercise, whilst delivering sufficient calories required for regenerating the body derived from $\mathrm{CHOs}$ contained within the powdered formulations, along with the added glucose and sucrose. Furthermore, the blackcurrant powders contain high levels of antioxidants such as polyphenols and vitamin C [30] that ameliorate the effects of oxidative stress brought upon by excessive physical exertion. They are an important source of nutrients for the body's needs and can also act as supplements. The fruit powder content for powders obtained by the spray-dried method ranged from 6 to $7 \%$, whilst this was 3 to $4 \%$ for the freeze-dried ones; this respectively corresponded to an equivalent 16 to $18 \%$ and 19 to $25 \%$ content when taking fresh fruit or blackcurrant juice into consideration. The spray-dried method gave a $60 \%$ lower juice content because $60 \%$ maltodextrin carrier is used for the preparation [30]. These aforementioned contents used in the designer drinks were established by pilot testing, taking an assumed total sugar content to provide an acceptable level of taste and appropriate osmolality. Greater amounts of powders added than those shown in Table 1 degraded the drink taste, which had to be counteracted by adding more $\mathrm{CHO}$. The $\mathrm{CHO}$ content of the designed drinks that included fruit powders and glucose or sucrose respectively ranged from 7.2 to $8.1 \%$ (after conversion taking into account the content of the soluble solids content and the total content of acids). These $\mathrm{CHO}$ values are comparable to those found in commercially available recovery beverages (ranging from 9.1 to $18.0 \mathrm{~g} / 100 \mathrm{~g}$ of drink) [11]. Functional beverages designed for athletes in order to enhance rehydration rates and delay fatigue should contain 40 to $80 \mathrm{~g} / \mathrm{L}$ of CHOs (optimally 60 to $80 \mathrm{~g} / \mathrm{L}$ ) [7]. CHO amounts greater than $80 \mathrm{~g} / \mathrm{L}$ in drinks may, however, slow gastric emptying and reduce intestinal water absorption during exercise when compared to beverages with lower $\mathrm{CHO}$ concentrations [7,22]. Electrolytes, $\mathrm{NaCl}$ and $\mathrm{KCl}$, added to the designed beverages gave respective concentrations of 0.1 to $0.2 \%$ (400 to $\left.800 \mathrm{mg} \mathrm{Na}^{+} / \mathrm{L}\right)$ and $0.025 \%\left(130 \mathrm{mgK}^{+} / \mathrm{L}\right)$, which were consistent with levels found in such drinks in other studies [3,7,22]. Brouns and Kovacs (1997) [7] state that sodium content should be higher than $400 \mathrm{mg} / \mathrm{L}$ (optimally $>600 \mathrm{mg} / \mathrm{L}$ ) and the recommended maximum content values for $\mathrm{Na}+$ and $\mathrm{K}+$ are, respectively, 1100 and $225 \mathrm{mg} / \mathrm{L}$.

Measured osmolalities, ranging from 401 to $564 \mathrm{mOsm} / \mathrm{kg} \mathrm{H}_{2} \mathrm{O}$, are presented in Table 2, along with those calculated from regression equations based on results obtained from individual drink components such as fruit powders, electrolytes, and CHOs. The obtained osmolality values were significantly different $(p<0.05)$ for each drink designed. Drink version 3 , which had low levels of 
added glucose (1\%) and 7\% spray-drying blackcurrant powder, gave the lowest osmolalities. The drink versions $2 a$ and $2 b$ had the same level of added ingredients and differed in the type of sweetener added (version 2a glucose; version $2 \mathrm{~b}$ sucrose). These drinks differed in osmolality, drinks with added sucrose had significantly lower osmolality values. Maltodextrin has lower osmolalities than glucose and sucrose and can be used in amounts up to $10 \%$ in recovery drinks designing [7]. The osmolalities in Table 2 demonstrate that the tested beverages are hypertonic, providing carbohydrates and rehydrating the body, and can so be particularly recommended after doing intensive exercise. Osmolalities in three designed drinks were low and ranged from 401 to $466 \mathrm{mOsm} / \mathrm{kg} \mathrm{H}_{2} \mathrm{O}$, whilst in the case of others the osmolalities were 557 to $564 \mathrm{mOsm} / \mathrm{kg} \mathrm{H}_{2} \mathrm{O}$. These values fell within the lower regions of the 500 to $800 \mathrm{mOsm} / \mathrm{kg} \mathrm{H}_{2} \mathrm{O}$ range considered adequate to rehydrate the body [7]. Ina study by Urdampillet et al. (2015) [22], characteristics of sports drinks were taken before, during, and after the training. Before: isotonic or slightly hypotonic ( 4 to $6 \%$ sugar and 0.5 to $0.7 \mathrm{~g} \mathrm{Na} / \mathrm{L}$ ), during: (6 to $9 \%$ sugars, 0.5 to $0.7 \mathrm{~g} \mathrm{Na} / \mathrm{L}$, and 0.7 to $1.2 \mathrm{~g} \mathrm{Na} / \mathrm{L}$ if longer than one hour or under heat stress), after: (9 to $10 \%$ sugars, 1 to $1.5 \mathrm{~g} \mathrm{Na} / \mathrm{L}$ ). The osmolarity of sports drinks taken during exercise had a minimum of 200 to a maximum of $330 \mathrm{mOsm} / \mathrm{L}$. According to this classification, the designed drinks should be classified as hypertonic sports drinks taken after the training. Calculated osmolalities of the test drinks obtained from the regression equations based on drinks components (Table 2) were higher by 14 to $33 \%$ than those measured; a likely reason is due to the interactions between individual drink components [22].

Table 2. Osmolalities of designed beverages.

\begin{tabular}{|c|c|c|}
\hline Beverage & Osmolalities Calculated by Regression Equations & Measured Osmolality \\
\hline Version 1 & $\begin{array}{c}\mathrm{OSM}=(15.33+29.19 \times 3)+(8.73+52.92 \times 5)+(8.30+ \\
\quad 330.42 \times 0.2)+(13.11+244.87 \times 0.025)=469.85\end{array}$ & $557.67 \pm 0.58 d$ \\
\hline Version $2 \mathrm{a}$ & $\begin{array}{c}\mathrm{OSM}=(15.33+29.19 \times 4)+(8.73+52.92 \times 5)+(8.30+ \\
\quad 330.42 \times 0.1)+(13.11+244.87 \times 0.025)=465.99\end{array}$ & $564.00 \pm 1.00 \mathrm{e}$ \\
\hline Version $2 b$ & $\begin{array}{c}\mathrm{OSM}=(15.33+29.19 \times 4)+(4.90+31.72 \times 5)+(8.30+ \\
30.42 \times 0.1)+(13.11+244.87 \times 0.025)=326.16\end{array}$ & $425.57 \pm 0.58 b$ \\
\hline Version 3 & $\begin{array}{c}\mathrm{OSM}=(7.00+24.55 \times 7)+(8.73+52.92 \times 1)+(8.30+ \\
330.42 \times 0.1)+(13.11+244.87 \times 0.025)=301.35\end{array}$ & $401.33 \pm 0.58 \mathrm{a}$ \\
\hline Version 4 & $\begin{array}{c}\mathrm{OSM}=(7.00+24.55 \times 6)+(8.73+52.92 \times 3)+(8.30+ \\
\quad 330.42 \times 0.1)+(13.11+244.87 \times 0.025)=382.35\end{array}$ & $436.33 \pm 0.58 c$ \\
\hline
\end{tabular}

The osmolality values (OSM) were calculated based on the sum of the osmolality values obtained from the regression equations (Figures 1-4) for the individual components used in designed drinks. The results are expressed as the mean of three replications $\pm \mathrm{SD}$; a-e-values marked by different letters differ significantly $(p<0.05)$.

Table 3 shows the physico-chemical properties of the designed drinks. The soluble solids containing solutes and non-volatile (e.g., mainly CHOs and acids) content ranged from $7.5 \mathrm{Bx}$ to $8.5^{\circ} \mathrm{Bx}$. Such soluble solids contents, $\mathrm{pH}$ and CHOs, were consistent with levels found in the literature for commercially available recovery beverages $[1,11]$.

Table 3. The soluble solids content, $\mathrm{pH}$, and acidity in the designed beverages.

\begin{tabular}{ccccc}
\hline The Tested Physico-Chemical Parameters & Version $\mathbf{1}$ & Version 2a,b & Version 3 & Version 4 \\
\hline Soluble solids content (Bx) & $7.50 \pm 0.00 \mathrm{a}$ & $7.50 \pm 0.25 \mathrm{a}$ & $8.00 \pm 0.46 \mathrm{a}$ & $8.50 \pm 0.20 \mathrm{~b}$ \\
\hline Acidity & $0.34 \pm 0.04 \mathrm{~b}$ & $0.53 \pm 0.01 \mathrm{a}$ & $0.55 \pm 0.07 \mathrm{a}$ & $0.36 \pm 0.04 \mathrm{~b}$ \\
\hline $\mathrm{pH}$ & $3.01 \pm 0.02 \mathrm{~b}$ & $3.01 \pm 0.01 \mathrm{~b}$ & $2.95 \pm 0.03 \mathrm{a}$ & $2.99 \pm 0.02 \mathrm{ab}$ \\
\hline
\end{tabular}

The results are expressed as the mean of three replications $\pm \mathrm{SD}$; $\mathrm{a}-\mathrm{d}-$ values marked by different letters differ significantly $(p<0.05)$.

Table 4 presents the content of vitamin C, polyphenols, and antioxidant activity in the designed drinks based on blackcurrant powders. Vitamin C content was high, ranging from 25 to $36 \mathrm{mg} / 100 \mathrm{~g}$, 
where consuming 250 to $300 \mathrm{~g}$ portions of these drinks would be sufficient to satisfy $100 \%$ of the body's requirement for this vitamin [31]. These drinks contained nutritionally significant amounts of polyphenol and antioxidant activity. Sadowska et al. (2019) [30] found that blackcurrant powders have high contents of polyphenols, vitamin $C$, and antioxidant activity. The study values determined correspond to those measured in the powders after accounting for the addition of water in accordance with each drink recipe [30].

Table 4. Bioactive compound content and antioxidant properties in the designed beverages.

\begin{tabular}{ccccc}
\hline Bioactive Compound and Antioxidant Properties & Version $\mathbf{1}$ & Version 2a,b & Version 3 & Version 4 \\
\hline Vitamin C (mg/100 g) & $25.83 \pm 0.3 \mathrm{a}$ & $34.45 \pm 0.7 \mathrm{~b}$ & $35.62 \pm 1.0 \mathrm{~b}$ & $26.71 \pm 0.4 \mathrm{a}$ \\
\hline Total polyphenols $(\mathrm{mg}$ GAE/100 g) & $43.11 \pm 0.2 \mathrm{a}$ & $57.47 \pm 0.1 \mathrm{c}$ & $62.50 \pm 0.1 \mathrm{~d}$ & $46.86 \pm 0.8 \mathrm{~b}$ \\
\hline Antioxidant properties (mmol TEAC/100 g) & $1.27 \pm 0.03 \mathrm{a}$ & $1.69 \pm 0.05 \mathrm{c}$ & $2.13 \pm 0.07 \mathrm{~d}$ & $1.60 \pm 0.01 \mathrm{~b}$ \\
\hline
\end{tabular}

The results are expressed as the mean of three replications $\pm \mathrm{SD}$; $\mathrm{a}-\mathrm{d}-$ values marked by different letters differ significantly $(p<0.05)$.

The sensory qualities of the designed drinks varied considerably (Figure 5, Table 5). The best tasting drinks (i.e., highest palatability) were ones containing the higher amounts of $\mathrm{CHOs}$ which may be related to their higher acidities and larger amounts of blackcurrant powder, particularly when prepared by lyophilization. Those drinks with added glucose or sucrose at the same $5 \%$ levels were however rated differently for taste. Sucrose-containing drinks were rated much more highly than those with glucose, which is consistent with sucrose having a more intensive sweetness to the human palate than glucose [32]. Particle palatability was not felt in beverages containing powders obtained by the spray-drying method. Overall quality of drinks was top for drink version $2 \mathrm{~b}$ containing sucrose and freeze-dried powder and drink version 4 with spray-drying powder (including $60 \%$ maltodextrin) and $3 \%$ glucose. Earlier studies of the authors [30] showed that the sensory quality of fruit drinks obtained with the use of powdered fruit (without the addition of $\mathrm{NaCl}$ ) is mainly influenced by the addition of sugar (preferably in the amount of $5 \%$ ).

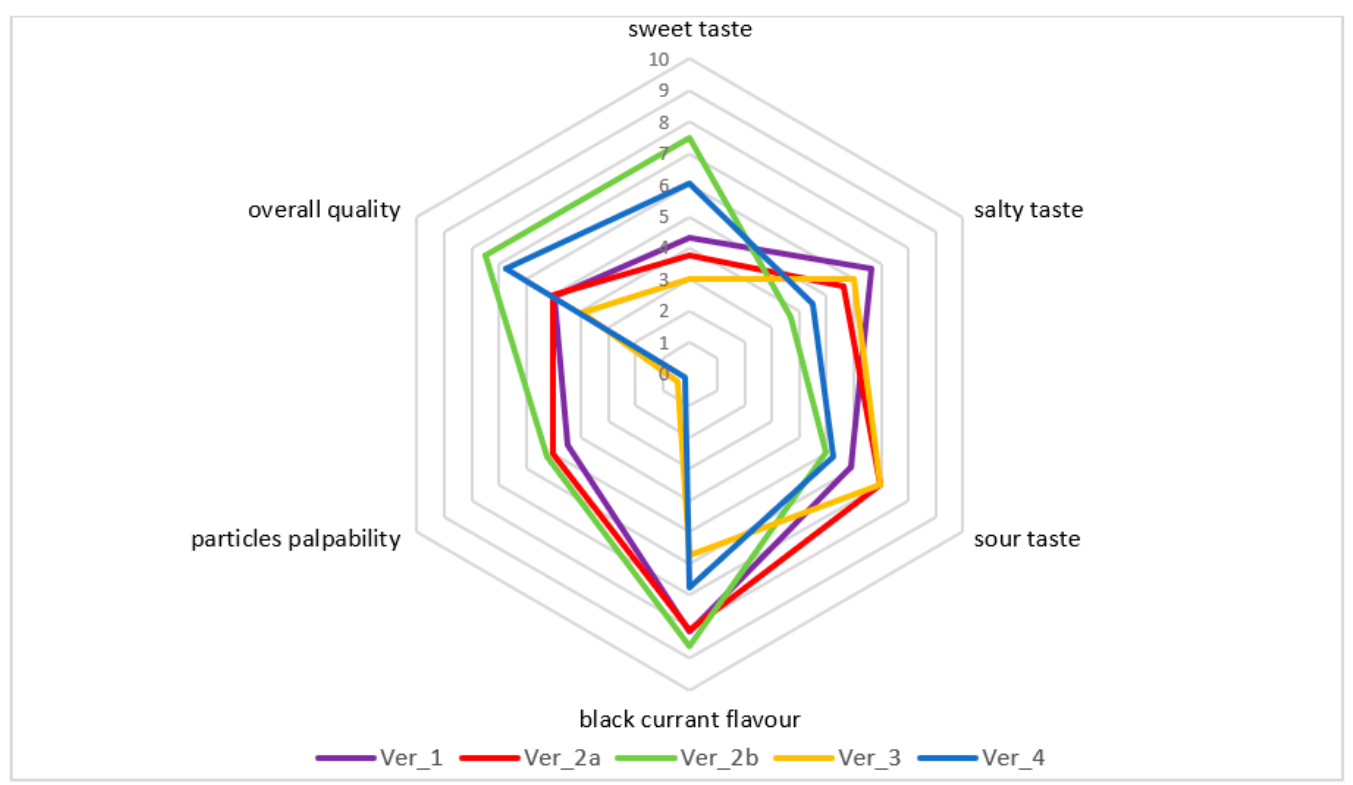

Figure 5. The sensory qualities of the designed recovery beverages. 
Table 5. Statistical analysis of the results obtained during the sensory evaluation of the designed recovery drinks; a-c-values marked by different letters differ significantly $(p<0.05)$, ${ }^{* * *}$ determinant of belonging of a given drink to a specific homogeneous group.

\begin{tabular}{|c|c|c|c|c|c|c|c|c|c|c|c|c|c|c|c|c|c|c|c|c|}
\hline \multicolumn{4}{|c|}{ Sweet Taste } & \multicolumn{4}{|c|}{ Salty Taste } & \multicolumn{4}{|c|}{ Sour Taste } & \multicolumn{3}{|c|}{ Blackcurrant Flavor } & \multicolumn{3}{|c|}{ Particles Palpability } & \multicolumn{3}{|c|}{ Overall Quality } \\
\hline Ver & $\mathbf{a}$ & b & c & Ver & $\mathbf{a}$ & $\mathbf{b}$ & c & Ver & $\mathbf{a}$ & $\mathbf{b}$ & c & Ver & $\mathbf{a}$ & $\mathbf{b}$ & Ver & a & $\mathbf{b}$ & Ver & $\mathbf{a}$ & b \\
\hline 3 & $* * *$ & & & $2 b$ & $* * *$ & & & $2 b$ & $* * *$ & & & 3 & $* * *$ & & 4 & $* * *$ & & $2 a$ & $* * *$ & \\
\hline $2 \mathrm{a}$ & $* * *$ & $* * *$ & & 4 & $* * *$ & $* * *$ & & 4 & $* * *$ & $* * *$ & & 4 & $* * *$ & & 3 & $* * *$ & & 1 & $* * *$ & \\
\hline 1 & $* * *$ & $* * *$ & & $2 a$ & & $* * *$ & $* * *$ & 1 & & $* * *$ & $* * *$ & 1 & & $* * *$ & 1 & & $* * *$ & 3 & $* * *$ & $* * *$ \\
\hline 4 & & $* * *$ & & 3 & & $* * *$ & $* * *$ & $2 a$ & & $* * *$ & $* * *$ & $2 \mathrm{~b}$ & & $* * *$ & $2 b$ & & $* * *$ & 4 & $* * *$ & $* * *$ \\
\hline $2 b$ & & & $* * *$ & 1 & & & $* * *$ & 3 & & & $* * *$ & $2 a$ & & $* * *$ & $2 a$ & & $* * *$ & $2 b$ & & $* * *$ \\
\hline
\end{tabular}

\section{Conclusions}

The study demonstrates the feasibility of preparing fruit recovery drinks containing electrolytes and carbohydrates, along with defined osmolalities, for these types of beverages. These designed drinks contained appropriate amounts of carbohydrates and electrolytes $\left(\mathrm{Na}^{+}\right.$and $\left.\mathrm{K}^{+}\right)$, as well as the desired osmolalities and carbohydrates content that accorded with both recommendations and the amounts found in commercially available recovery drinks. They also contain nutritionally valuable bioactive components such as vitamin $C$ and polyphenols as derived from the blackcurrant powders (obtained by either freeze- or spray-drying). Furthermore, their sensory qualities are satisfactory even though the levels of electrolytes match those found in recovery drinks. A linear relationship was found between beverage component content with osmolality. These outcomes may be useful in designing those functional sports drinks both ones without fruit components and ones that are innovative fruit recovery drinks.

Author Contributions: Conceptualization, A.S.; methodology, A.S.; formal analysis, A.S. and W.L.; investigation, A.S.; writing-original draft preparation, A.S. and F.Ś.; writing—review and editing, A.S. All authors have read and agreed to the published version of the manuscript.

Funding: This research received no external funding.

Conflicts of Interest: The authors declare no conflict of interest.

\section{References}

1. Sadowska, A.; Świderski, F.; Rakowska, R.; Waszkiewicz-Robak, B.; Żebrowska-Krasuska, M.; Dybkowska, E. Beverage osmolality as a marker for maintaining appropriate body hydration. Rocz. Panstw. Zakl. Hig. 2017, 68, 167-173. [PubMed]

2. Faria, D.K.; Mendes, M.E.; Sumita, N.M. The measurement of serum osmolality and its application to clinical practice and laboratory: Literature review. J. Bras. Patol. Med. Lab. 2017, 53, 38-45. [CrossRef]

3. Pound, C.M.; Blair, B. Energy and sports drinks in children and adolescents. Paed. Child Health-Can. 2017, 22, 406-410. [CrossRef] [PubMed]

4. American Academy of Pediatrics; Committee on Nutrition and the Council on Sports Medicine and Fitness. Sports drinks and energy drinks for children and adolescents: Are they appropriate? Pediatrics 2011, 127, 1182-1189. [CrossRef]

5. Campbell, B.; Wilborn, C.; La Bounty, P.; Taylor, L.; Nelson, M.T.; Greenwood, M.; Ziegenfuss, T.N.; Lopez, H.L.; Hoffman, J.R.; Stout, J.R.; et al. International Society of Sports Nutrition position stand: Energy drinks. J. Int. Soc. Sports Nutr. 2013, 10, 1. [CrossRef] [PubMed]

6. Rotstein, J.; Barber, J.; Strowbridge, C.; Hayward, S.; Huang, R.; Godefroy, S.B. Energy drinks: An assessment of the potential health risks in the Canadian context. Int. Food Risk Anal. J. 2013, 3, 1-29. [CrossRef]

7. Brouns, F.; Kovacs, E. Functional drinks for athletes rewiev. Trends Food Sci. Technol. 1997, 8, 414-421. [CrossRef]

8. Febbraio, M.A.; Snow, R.J.; Stathis, C.G.; Hargreaves, M.; Carey, M.F. Effect of heat stress on muscle energy metabolism during exercise. J. Appl. Physiol. 1994, 77, 2827-2831. [CrossRef]

9. Nielsen, B. Temperature Regulation; Effects of sweat loss during prolonged exercise. Acta Physiol. Stand. 1986, 128, 105-109. 
10. Sawka, M.N. Physiological consequences of hypohydration: Exercise performance and thermoregulation. Med. Sci. Sports Exerc. 1992, 24, 657-670. [CrossRef]

11. Mettler, S.; Rusch, C.; Colombani, P.C. Osmolality and pH of sport and other drinks available in Switzerland. Schweiz. Z. Sportmed. Sporttraumatol. 2006, 54, 92-95.

12. Evans, G.H.; Shirreffs, S.M.; Maughan, R.J. Postexercise rehydration in man: The effects of osmolality and carbohydrate content of ingested drinks. Nutrition 2009, 25, 905-913. [CrossRef] [PubMed]

13. Leiper, J.B. Intestinal water absorption-implications for the formula-tion of rehydration solutions. Int. J. Sport Med. 1998, 19, 129-132. [CrossRef] [PubMed]

14. Farthing, M.J. Oral rehydration: An evolving solution. J. Pediatr. Gastro-Enterol. Nutr. 2002, 34, 64-67. [CrossRef]

15. Hiller, W.D.B. Dehydration and hyponatremia during triathlons. Med. Sci. Sports Exerc. 1989, 21, $222-237$.

16. Noakes, T.D.; Norman, R.J.; Buck, R.H.; Godlonton, J.; Stevenson, K.; Pittaway, D. The incidence of hyponatremia during prolonged ultraendurance Exercise. Med. Sci. Sports Exerc. 1990, 22, 165-170.

17. Noakes, T.D. Hyponatremia during endurance running: A Physiological and Clinical Interpretation. Med. Sci. Sports Exerc. 1993, 24, 403-405. [CrossRef]

18. Gisoffi, C.V.; Summers, R.W.; Schedl, H.P.; Bleiler, T.L. Intestinal water absorption from select carbohydrate solutions in humans. J. Appl. Physiol. 1992, 73, 2142-2150. [CrossRef]

19. Hawley, J.A.; Dennis, S.C.; Noakes, T.D. Oxidation of carbohydrate ingested during prolonged endurance exercise. Sports Med. 1992, 14, 27-42. [CrossRef]

20. Rehrer, N.; Wagenmakers, A.J.; Beckers, E.J.; Halliday, D.; Leiper, J.B.; Brouns, F.; Maughan, R.J.; Westerterp, K.; Saris, W.H. Gastric emptying, absorption, and carbohydrate oxidation during prolonged exercise. Appl. Physiol. 1992, 72, 468-475. [CrossRef]

21. Wagenmakers, A.J.M.; Brouns, F.; Saris, W.H.; Halliday, D. Oxidation rates of orally ingested carbohydrates during prolonged exercise in men. Appl. Physiol. 1993, 75, 2774-2780. [CrossRef] [PubMed]

22. Urdampilleta, A.; Gómez-Zorita, S.; Soriano, J.M.; Martínez-Sanz, J.M.; Medina, S.; Gil-Izquierdo, A. Hydration and chemical ingredients in sport drinks: Food safety in the European context. Nutr Hosp. 2015, 31, 1889-1899. [PubMed]

23. PN-EN 12147:2000. Fruit and Vegetable Juices-Determination of Titrable Acidity; Polish Committee for Standardization: Warszawa, Poland, 2000.

24. Re, R.; Pellegrini, N.; Proteggente, A.; Pannala, A.; Yang, M.; Rice-Evans, C. Antioxidant activity applying an improved ABTS radicalcation decolorization assay. Free Radic. Biol. Med. 1999, 26, 1231-1237. [CrossRef]

25. Singleton, V.; Rossi, J. Colorimetry of total phenolics withphosphomolybdic-phosphotungstic acid reagents. Am. J. Enol. Viticult. 1965, 16, 144-158.

26. ISO PN-EN ISO 13299:2016-05. Sensory Analysis-Methodology-General Guidelines for Determining the Sensory Profile; ISO: Geneva, Switzerland, 2016.

27. PN-EN ISO 8586:2014-03. Sensory Analysis-General Guidelines for the Selection, Training and Monitoring of Selected Assessors and Sensory Evaluation Experts; ISO: Geneva, Switzerland, 2012.

28. PN-EN ISO 8589:2010/A1:2014-07. Sensory Analysis-General Guidelines for Designing a Sensory Analysis Laboratory; ISO: Geneva, Switzerland, 2007.

29. Santos, L.S.; Ferreira-Bonomo, R.C.; Lemos, A.R.; da Costa Ilheu Fontain, R.; Santos, W.O.; Veloso, C.M.; Souza, M.A. Influence of concentration and type of sugar additives on the osmolality and acceptance of coconut water. UNOPAR Cient Ciênc Biol. Saúde 2011, 13, 29-32.

30. Sadowska, A.; Rakowska, R.; Świderski, F.; Kulik, K.; Hallmann, E. Properties and microstructure of blackcurrantpowders prepared using a new method offluidized-bed jet milling and drying versus otherdrying methods. CyTA J. Food. 2019, 17, 439-446. [CrossRef]

31. Regulation No 1169/2011 of the European Parliament and of the Council (UE) of 25 October 2011 on the provision of food information to consumers. Off. J. Eur. Union 2011, 20, 168-213.

32. Rao, L.J.M.; Ramalakshmi, K. (Eds.) Ingredients of soft drinks. In Recent Trends in Soft Beverages; Woodhead Publishing: India, New Delhi, 2011; pp. 189-209.

Publisher's Note: MDPI stays neutral with regard to jurisdictional claims in published maps and institutional affiliations. 